\title{
Consequence of Hydrocarbon Haze Formation on Global Carbon Cycle under Anoxic and Mildly Oxidized Environment
}

\author{
YASUTO WATANABE ${ }^{\prime}$, EIICHI TAJIKA ${ }^{1}, \mathrm{KAZUMI} \mathrm{OZAKI}^{2}$,
} PENG K. HONG

Department of Earth and Planetary Science, the University of Tokyo, Japan (*correspondence: yasuto@eps.s.utokyo.ac.jp)

Department of Environmental Science, Toho University, Japan

${ }^{3}$ Planetary Exploration Research Center, Chiba Institute of Technology, Japan

The atmospheric oxygen level $\left(\mathrm{pO}_{2}\right)$ in the Archean $(4.0-2.5 \mathrm{Ga})$ is suggested to have been much lower than $10^{-}$ 5 PAL (present atmospheric level) [1]. In sufficiently reducing atmosphere $\left(\mathrm{CH}_{4} / \mathrm{CO}_{2}>\sim 0.2\right)$, hydrocarbon haze may be formed [2]. In the Late Archean, while some geological records suggest temporal increase of $\mathrm{pO}_{2}$ [3], another suggests a transient haze formation [4]. However, influence of the haze formation on the global carbon cycle has not been fully investigated. Here we used a coupled model of atmospheric photochemistry-marine microbial ecosystem-global carbon cycle, including a photochemical model "Atmos" [2], to investigate the effects of hydrocarbon haze formation on global carbon cycle under completely anoxic condition in the Middle Archean $\left(\mathrm{pO}_{2}<\right.$ $10^{-10}$ PAL) and mildly oxidized condition in the Late Archean $\left(\mathrm{pO}_{2} \sim 10^{-6} \mathrm{PAL}\right)$. We found that, removal of haze particles due to rainout from the atmpshere works as an effective $\mathrm{CO}_{2}$ consumption pathway in completely anoxic atmosphere, which makes the climate unstable. In the mildly oxidized world, however, the haze formation rate was not affected significantly by the change in $\mathrm{pCO}_{2}$, suggesting that there is a negative feedback mechanism concerning the haze formation rate through changes in the UV flux in the atmosphere and atmospheric redox condition. As a result, the hazy climate state could be stable under such a mildly oxidized condition. Our result is consistent with the geological record that suggests a transient formation of hydrocarbon haze in the Late Archean.

[1] Pavlov and Kasting (2002), Astrobiology 2(1), 27-41.

[2] Arney et al. (2016), Astrobiology 16(11), 873-899.

[3] Anbar et al. (2007), Science 317(5846), 1903-1906.

[4] Izon et al. (2017), PNAS 114(13), E2571-E2579. 